\section{ER-014 EDUCATION OF PATIENTS RECEIVING OXYGEN THERAPY}

${ }^{1} E$ Delande ${ }^{*},{ }^{1} T$ Mékidèche, ${ }^{2} R$ Bouzioukh, ${ }^{2} \mathrm{~L}$ Mely, ${ }^{1} \mathrm{~B}$ Mandy. ${ }^{1}$ Renée Sabran HospitalHospices Civils De Lyon, Pharmacy, Hyeres, France; ${ }^{2}$ Renée Sabran Hospital-Hospices Civils De Lyon, Respiratory Illness Service and Cystic Fibrosis Ressources and Compétences Centre, Hyeres, France

\subsection{6/ejhpharm-2020-eahpconf.449}

Background and importance Oxygen is a dangerous medication because of its oxidising properties. Its use can be difficult for patients with respiratory insufficiency. Because of the impact on quality of life, oxygen dependent patients have low therapeutic adherence. This can lead to an increase in rehospitalisations and comorbidities. We have proposed educational sessions about the proper use of oxygen for these patients.

Aim and objectives The aim of the study was to build educational sessions and assess their impact on patient knowledge.

Material and methods The course was a collaboration between pharmacists, pulmonologists, physiotherapists, nurses and an oxygen provider service. It dealt with pathophysiology, oxygen safety, different types of equipment and travelling with oxygen. The sessions took 2 hours, once a month, and involved all patients receiving oxygen therapy in the institution. A hospital pharmacist and a pharmacist from the oxygen provider service moderated the course. Surveys were given to patients during these session to characterise the population, to measure the improvement in their knowledge before/after the course and to assess their satisfaction.

Results We collected data from 43 patients. Mean age was 66.1 years and the sex ratio was 1.26 . A total of $67.4 \%$ of patients used liquid equipment, $74.4 \%$ for at least 1 year: $48.8 \%$ of patients were hospitalised for pulmonary causes during the last year, $60.5 \%$ of patients had never had any education about oxygen therapy and $32.6 \%$ went out without their oxygen.

The progression of patients was 4.6 points out of 20 after the educational sessions. The difference was significant $(\mathrm{p}<0.01$, unilateral Student's test, paired values). All patients were satisfied with the educational sessions but $20.9 \%$ said they had concentration difficulties.

Conclusion and relevance Oxygen is a treatment with limited compliance due to its impact on the quality of life of patients. The use of this essential medication must be considered at risk because it requires safety information and can cause disorders if misused. The results of this study highlight the interest in educational sessions for patient care.

\section{REFERENCES AND/OR ACKNOWLEDGEMENTS}

1. Jacobs SS, Lindell KO, Collins EG, et al. Patient perceptions of the adequacy of supplemental oxygen therapy. Ann Am Thorac Soc 2018;15:24-32.

No conflict of interest.

\section{ER-015 RISKS OF PHARMACIST RECOMMENDED ANTIBIOTIC USE: GENERAL PUBLIC PERCEPTION}

${ }^{1} \mathrm{M}$ Attard Pizzuto, ${ }^{2} \mathrm{~S}$ Hatzel, ${ }^{1} \mathrm{LM}$ Azzopardi*. 'University of Malta, Department of Pharmacy, Msida, Malta; ' University of Bonn, Department of Pharmacy, Bonn, Germany

\subsection{6/ejhpharm-2020-eahpconf.450}

Background and importance Pharmacists, being highly accessible healthcare professionals, can handle requests by patients for pharmacist recommended medicines and refer to physicians when prescription medications or further assessment is required. This study seeks to establish whether patients are ready to trust the pharmacist with the prescribing of medicines and whether patients associate pharmacist prescribing with risks.

Aim and objectives To assess public perception regarding the risks of potential antibiotic prescribing by pharmacists.

Material and methods A pre-validated questionnaire was used. ${ }^{1}$ The questionnaire was disseminated to the general public in shopping malls and popular shopping streets over a 4 week period in Malta. Statistical analysis was undertaken using Statistical Package for the Social Sciences (SPSS) V.25.

Results A total of 400 participants completed the questionnaire (51\% women, $33 \%$ aged $>60$ years). Forty-four per cent of participants stated they always visited the same pharmacy. Older participants $(\geq 60$ years) tended to visit the same pharmacy more often than the younger age group $(p<0.001)$. Seventeen per cent admitted to asking their pharmacist for antibiotics without a doctor's prescription and 51\% expected to be prescribed antibiotics on visiting a doctor when they felt they had symptoms of an infection. Forty-two per cent associated a risk to patients if pharmacists were to recommend a selected number of antibiotics.

Conclusion and relevance The expectations of patients to be prescribed antibiotics as soon as they feel symptoms of an infection need to be addressed through proper education. There is a perception of risk with the prescribing of antibiotics by pharmacists.

\section{REFERENCES AND/OR ACKNOWLEDGEMENTS}

1. Attard Pizzuto M, Sivridas M, Serracino-Inglott A, Azzopardi LM, Bouvy ML. Public perception of antibiotic prescribing by pharmacists. Poster presented at FIP, Seoul, South Korea, 2017.

No conflict of interest.

\section{ER-016 ECONOMIC VALUE OF UNUSED HIGH COST EXPERIMENTAL INFUSION DRUGS: A POTENTIAL SAVING FOR THE NATIONAL HEALTH SYSTEM}

${ }^{1}$ SL Borchetto*, 'B Taddei, ${ }^{2} \mathrm{~F}$ Marchesi, ${ }^{1} \mathrm{~S}$ Nozza, ${ }^{1} \mathrm{~F}$ Gregis, ${ }^{1} \mathrm{~V}$ Gatti, ${ }^{1} \mathrm{~L}$ Rossi. ${ }^{1}$ Asst Papa Giovanni XXIII, Uoc Farmacia, Bergamo, Italy; ${ }^{2}$ Asst Papa Giovanni XXIII, Uoc Oncologia, Bergamo, Italy

\subsection{6/ejhpharm-2020-eahpconf.451}

Background and importance Antineoplastic and immune-modulatory drugs are top for public pharmaceutical spending. About half of the clinical trials conducted in Italy concern oncohaematology, with an important investment by big pharma and a source of savings for the national health system (NHS). According to GCPs and the regulation (EU) N. 536/ 2014, pharmacists are involved in traceability, storage, return and destruction of investigational medicinal products to ensure their quality, the safety of the subjects involved, and the reliability and robustness of the data.

Aim and objectives To quantify the economic value of unused infusion drugs at our centre.

Material and methods To guarantee the traceability system, we used a database for all of the main information regarding the drug (product description, batch number, expiry date, location, storage condition) and its accountability (status change date, received, used, available, kit, subject ID, shipment/cycle/ returned/destroyed). The analysed data were collected from January 2018 to October 2019 for the clinical trials managed 